\title{
Fast Power Routing through HVDC
}

\author{
Haiping Yin, Student Member, IEEE, Lingling Fan, Senior Member, IEEE, Zhixin Miao, Senior Member, IEEE
}

\begin{abstract}
The objective of this paper is to investigate fast power routing capability of line current commutating (LCC)HVDC. Such capability is most desired in future grids with high penetration of renewable energy sources (e.g., wind and solar). The technology presented in this paper replaces the traditional LCC-HVDC rectifier power order control by an ac voltage mode control. This technology enables the HVDC rectifier ac bus to act as an infinite bus and absorb fluctuating wind power. $A$ study system consisting of an ac system, an LCC-HVDC, and a doubly-fed induction generator (DFIG) based wind farm is built in Matlab/SimPowersystems. Simulation studies are carried out to demonstrate the proposed HVDC rectifier control in routing fluctuating wind power and load change. Parameters of the proposed voltage mode control are investigated to show their impact on HVDC power routing and ac fault recovery.
\end{abstract}

Index Terms-Doubly fed induction machine (DFIG), highvoltage direct current (HVDC),

\section{INTRODUCTION}

$\mathbf{F}$ AST power routing capability is most desired for future grids with high penetration of renewable energy resources such as wind and solar. Due to their intermittent nature, power flow patterns in future grids will experience fluctuation more often. This poses challenges in system operation to manage congestion in a fast speed fashion. Flexible AC Transmission Systems (FACTS) and HVDC are two enabling technologies with fast power routing capabilities. HVDC has been an option to interconnect wind farms to ac grids [1]-[3]. There are currently voltage source converter (VSC)-based HVDC for mid-voltage level transmission [4] and LCC-HVDC for highvoltage level transmission [5].

The objective of this paper is to investigate the fast power routing capability of LCC-HVDC since LCC-HVDC is a mature technology in high power high voltage transmission and have been used world wide. The term fast power routing refers to the capability of HVDC routing wind power fast enough to avoid local synchronous generators to pick up the power change. Traditionally, LCC-HVDC is equipped with current order control at its rectifier side [6]. The current reference is computed from the power order divided by the measured direct voltage. Therefore, power delivered through HVDC can be scheduled. This research aims to examine a new way to enable fast power routing by HVDC. Power scheduling does not suit for this aim since the power flow patterns keep changing and the power order should keep changing. Communication links are required to send the varying power order from wind farms to HVDC links. Additional computing time and communication time are needed. An HVDC is expected to

This work was supported in part by the National Science Foundation under Grant ECCS 1005277. H. Yin, L. Fan and Z. Miao are with the Department of Electrical Engineering, University of South Florida, Tampa, FL 33620 (Emails: hyin@mail.usf.edu; linglingfan@usf.edu; zmiao@usf.edu). respond in a fast fashion. Therefore, an automatic control using local measurements is expected.

The concept of infinite bus is implemented in designing such kind of automatic control. An infinite bus can absorb or generate whatever power the rest of the system needed. To emulate an infinite bus, the ac bus at the rectifier side of an HVDC should be controlled to have a constant voltage. Therefore, a voltage mode control should replace the traditional power scheduling to realize fast power routing capability.

Compared with the existing literature on HVDC and wind farm power coordination [7]-[9], the study scope is very different. This research investigates fast power routing for an area with combined conventional power plants and wind farms. The HVDC system is designed to route wind power to the grid from this area. Power routing control design for the HVDC system should coordinate the wind farm, the HVDC system and the conventional power plant. While in the existing literature, the purpose of an HVDC system is to deliver wind energy to the grid only. Coordination with the conventional generators is not considered.

Also compared with the existing literature on HVDC and wind farm power coordination, the aforementioned approach has the following advantages:

1) The control does not rely on additional devices such as STATCOM. STATCOM converter are used for wind farms with HVDC delivery to provide reactive power [7], [10]-[12]. The dc-link voltage of a STATCOM reflects the power unbalance between wind farms and an HVDC link. Hence the dc-link voltage is used as a feedback signal to adjust the HVDC rectifier current order. In this paper, since a hybrid ac/dc system is the study objective, synchronous source is presented at the wind farm side. Therefore, STATCOM is not needed and none of its measurements is available for controls.

2) There is no change required at the DFIG control side. In [8], [9], power balance between a DFIG wind farm and an HVDC is realized through frequency control. A frequency control is applied to give a current order in the rectifier control. Changes have to be made at DFIG controls. Instead of real/reactive power control, stator flux control is adopted.

The rest of the paper is organized as follows. Section II presents the study system. Section III presents the proposed HVDC control. Section IV presents simulation studies and Section V concludes the paper.

\section{Study System}

The study system is shown in Fig. 1. The system consists of a $1000 \mathrm{MW}$ synchronous generator, a $510 \mathrm{MW}$ wind farm and an LCC-HVDC with a rated power at $1000 \mathrm{MW}$. The system 


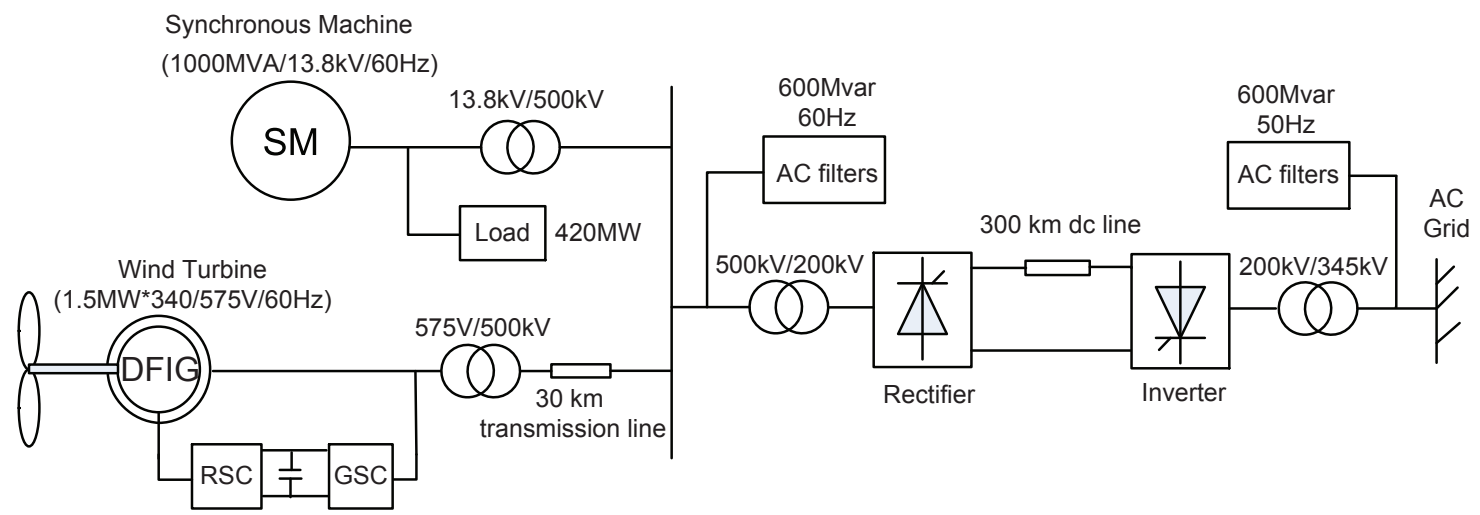

Fig. 1. Study system.

is built in Matlab/SimPowerSystems [13]. The HVDC link and the synchronous generator are built based on the models from SimPowerSystems examples . A 1.5 MW DFIG is scaled up to represent a 510 MW DFIG wind farm. Power from the synchronous generator and the wind farm is transmitted to a $50 \mathrm{HZ}$ grid through an LCC-HVDC connection. AC filters on the two terminals of the HVDC are applied to eliminate the harmonics in the ac currents. They can also provide reactive power for HVDC converters. The size of the ac filter at both converter sides is 600 MVar including 150 MVar from a shunt capacitor, 150 MVar from an 11th harmonic filter, 150 MVar from a 13th harmonic filter and 150 MVar from a 24th harmonic filter. The HVDC is a $1000 \mathrm{MW}$ $(500 \mathrm{kV}, 2 \mathrm{kA}) \mathrm{dc}$ link. The converters of HVDC are connected through a $300 \mathrm{~km}$ transmission line. Detailed parameters of the DFIG, synchronous generator, HVDC and transformers can be referred to SimPowerSystems user's guide [13].

\section{A. Turbine-governor model of the synchronous generator}

The schematic diagram of the turbine-governor model of the synchronous generator is shown in Fig. 2 [14]. It consists of a hydraulic turbine, a second-order servomotor system and power/frequency controls. $\Delta \omega$ is the speed deviation of the speed measurement with respect to the nominal value. The input of the PID controller is the sum of the speed error signal and the power error multiplied by a droop (5\%). The output of the PID controller drives the servo motor to change the valve position of the hydraulic turbine. As the result of the

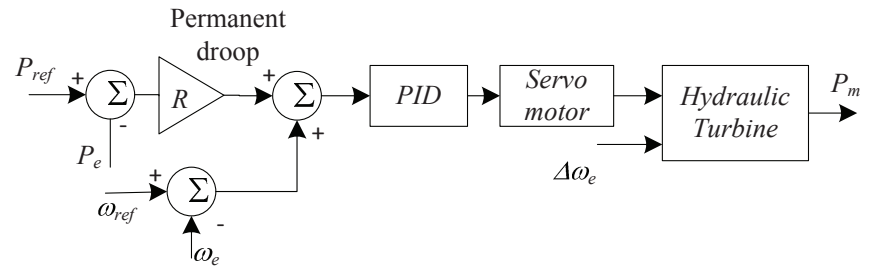

Fig. 2. Turbine-governor.

power/frequency control, the synchronous generator can adjust its exporting power based on the frequency deviation and the power deviation. At stead state, the error signal fed into the
PID controller should be zero:

$$
\text { error }=-R \Delta P_{e}-\Delta \omega_{e}=0
$$

where $R$ is the droop parameter. When the system is subject to a disturbance, the synchronous generator power and the generator speed are subject to variations. This will also lead to dynamics in the mechanical power.

\section{B. Wind turbine}

A 9MW wind farm model is included in an example of SimPowerSystems. For this project, the 9MW wind farm model is scaled up to represent 340 DFIG wind turbines each at 1.5 MW. The wind farm is operated at maximum power point tracking mode when the wind speed is less than the nominal wind speed. When the wind speed is above rated speed, pitch angle control will regulate the aerodynamic torque. In such conditions, the mechanical power is reduced to the rating $(1 \mathrm{pu})$ through adjusting the pitch angle. A typical structure of pitch angle controller is shown in Fig. 3 [15]. The pitch angle is determined by the input variables: the rotor speed and the electirc power.

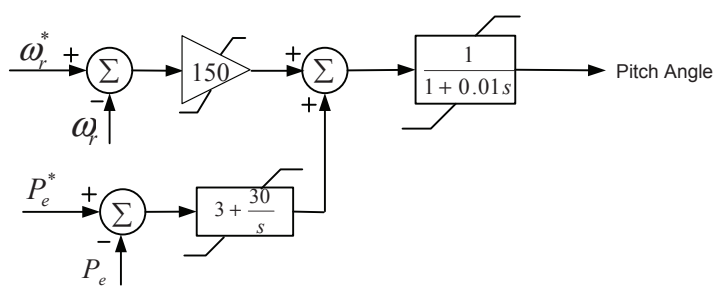

Fig. 3. Wind turbine pitch angle controller.

\section{Control of RSC and GSC}

The control objectives of the rotor side converter (RSC) are to regulate the electromagnetic torque and the stator reactive power. The torque order is obtained from maximum power point tracking. There are two cascaded control loops: the inner fast loop is current control and the outer slow loop is power/torque control. 

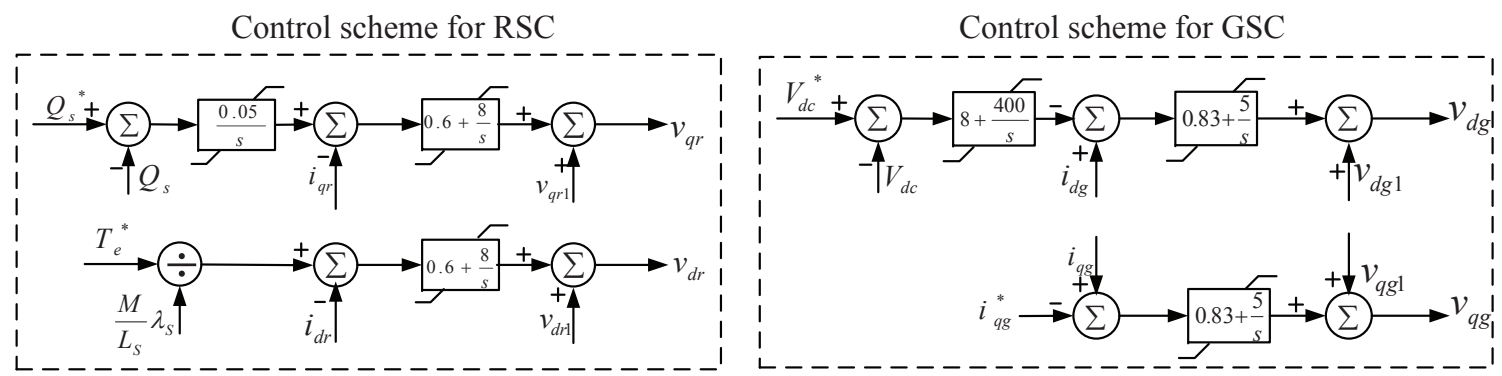

Fig. 4. Control scheme for RSC and GSC: $v_{q r 1}=-\omega_{s l i p} \sigma L_{r} i_{d r}, v_{d r 1}=-\omega_{s l i p}\left(\sigma L_{r} i_{q r}+M / L_{s} \lambda_{s}\right), v_{q g 1}=v_{q s}-\omega_{s} L_{t g} i_{d g}, v_{d g 1}=v_{d s}+\omega_{s} L_{t g} i_{q g}$.

The expression of the stator voltage $v_{s}$ in complex vector in a synchronous qd reference frame can be expressed as:

$$
v_{s}=r_{s} i_{s}+\frac{d \lambda_{s}}{d t}+j \omega \lambda_{s}
$$

where $r_{s}, i_{s}, \lambda_{s}$ are stator resistance, current vector and flux linkage vector.

As the basic control of DFIG is based on the stator voltage orientated control, where the d-axis is aligned with the stator voltage, which means $v_{d s}=v_{s}$ and $v_{q s}=0$. Under steadystate, and ignore the stator resistance, the stator voltage will be:

$$
v_{s}=j \omega \lambda_{s}
$$

where $\lambda_{s}=j \lambda_{q s}, \lambda_{d s}=0$. The expressions of stator active and reactive power are as follow:

$$
P_{s}+j Q_{s}=\frac{2}{3} v_{s} i_{s}^{*}=\frac{2}{3} j \omega \lambda_{s}\left(\frac{\lambda_{s}-L_{m} i_{r}}{L_{s}}\right)^{*}
$$

where $L_{m}, L_{s}, i_{r}$ are the magnetizing inductance, stator inductance and rotor current vector and $\lambda_{s}=L_{s} i_{s}+L_{m} i_{r}$. Hence $P_{s}=\frac{\omega L_{m}}{L_{s}} \lambda_{q s} i_{d r}$ and $Q_{s}=\frac{\omega \lambda_{q s}^{2}}{L_{s}}-\frac{\omega \lambda_{q s}}{L_{s}} L_{m} i_{q r}$.

Hence, the rotor current component $i_{d r}$ could be regulated through the electromagnetic torque $T_{e}\left(P_{s} / \omega\right)$ divided by $\lambda_{s}$. On the other hand, the q-axis component $i_{q r}$ can be regulated through the stator reactive power $Q_{s}$. Hence, the outer power control loop could be designed to get the reference value of the rotor current.

In the grid side converter (GSC) control, the dc voltage of the dc-link between the RSC and the GSC could be kept constant. The reactive power generated by the GSC could also be regulated. The inner current control loops are used to limit converter currents. Feed forward is used to decouple the dynamics qd-axis currents. The PI controller parameters are selected to achieve a bandwidth of at least $100 \mathrm{~Hz}$ [16], [17]. The RSC and GSC control loops are shown in Fig. 4.

\section{HVDC CONTROL}

The control diagram of the HVDC is shown in Fig. 5. Controls are implemented for both the rectifier and the inverter. For inverter control, there are three types of modes constant dc voltage, constant extinction angle and constant dc current. PI controllers are implemented to regulate dc voltage, extinction angle or dc current. Voltage dependent current limiter (VDCL) will be enforced when the dc voltage drops due to ac disturbances [5], [6]. For this study system, the HVDC inverter is operated at the constant voltage control mode at normal operating conditions.

The rectifier is normally operated at the constant current control mode where the dc current measurement is compared with a dc current order to generate desired firing angle. A positive feedback PI controller is adopted due to the LCCHVDC characteristic. A brief description is as follows. The relationship among the firing angle $\alpha_{R}$ of the rectifier, rectifier side ac voltage magnitude $V_{a c}$, dc voltage $V_{d r}$ and dc current $I_{d R}$ is expressed as:

$$
V_{d r}=2.7 V_{a c} \cos \alpha_{R}-I_{d R} * R_{c}
$$

Also the voltage and current relationship of the dc line is as follows:

$$
V_{d r}=V_{d i}+I_{d R} * R_{d c} .
$$

where $V_{d i}$ is the inverter side dc voltage. Therefore $I_{d R}=$ $\frac{2.7 V_{a c} \cos \alpha_{R}-V_{d i}}{R_{c}+R_{d c}}$. Assume that $V_{a c}$ and $V_{d i}$ are constant. If the firing angle $\alpha$ increases, $I_{d R}$ decreases. Therefore, a positive feedback control is reasonable. To improve the dc current, the firing angle should be reduced. The measured dc current is compared with the dc current reference and the error signal is fed into a PI controller (shown in Fig. 5). The output of the controller is the firing angle at the rectifier side $\alpha_{R}$. In traditional HVDC rectifier control, this current order is generated by the dc power order divided by the dc voltage. The bandwidth of the current order control for LCC-HVDC system is at least $40 \mathrm{~Hz}$ [10].

When there is an ac system fault, the inverter may not be able to recover itself due to commutation failure. In such cases, it is important to reduce the stress on the inverter valves. This is achieved by reducing the rectifier side dc voltage $v_{d r}$. When the rectifier side dc voltage $v_{d r}$ reaches a limit $V_{d L_{R}}$, the voltage dependent current order limiter (VDCOL) starts to work. The VDCOL reduces the current setting when the voltage decreases.

The traditional power scheduling way to adjust the current order is not feasible for the purpose of fast power routing with wind power involved. Since wind power is fluctuating, a constant power schedule is difficult to implement. In this paper, a new rectifier control is proposed for the HVDC to follow the fluctuating wind power and route the wind power to a grid. 
Rectifier control
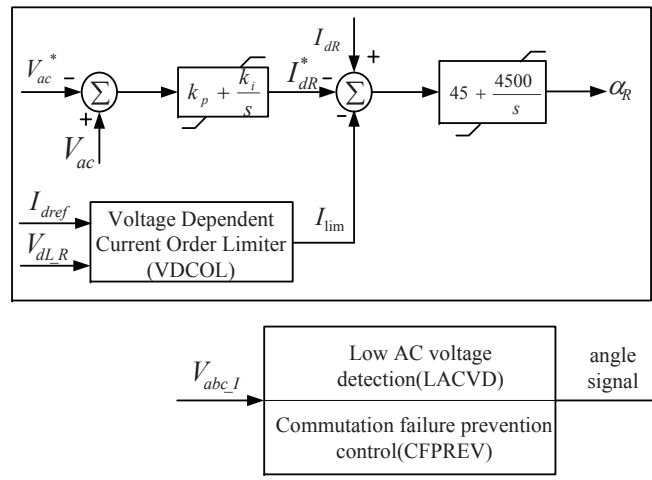

Inverter control

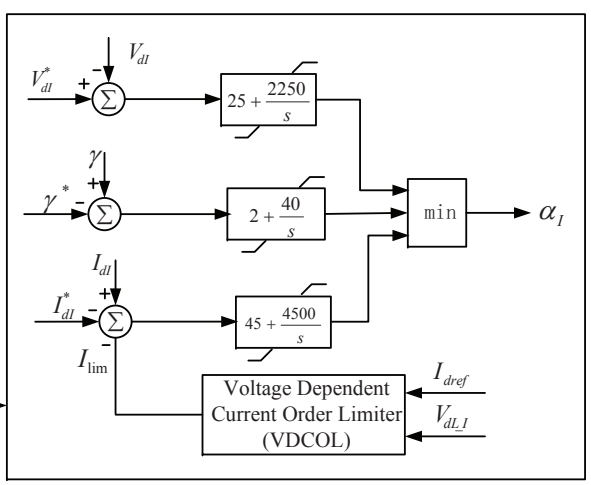

Fig. 5. Control scheme for HVDC.

\section{A. Proposed HVDC rectifier voltage control}

Three major concerns will be addressed in this subsection: 1) why a positive feedback control is adopted for voltage mode control; 2) why such a feedback control system will result in an stable system; and 3) why the rectifier bus can be viewed as an infinite bus.

Compared with the conventional power control at the rectifier, the proposed control uses voltage control to generate $\mathrm{dc}$ current reference. The RMS value of the ac voltage at the rectifier is measured and compared with a reference ac voltage $V_{a c}^{*}$. The error is sent to a PI controller to generate a dc current order $I_{d R}^{*}$. A positive feedback control is implemented for the voltage control in Fig. 5. Justification of the positive feedback control is presented as follows.

For the study system, a simplified circuit model is presented in Fig. 6. The synchronous generator is simplified as a voltage source $V_{G}$ behind an impedance $Z_{G}$, while the aggregated wind farm is considered as a current source $I_{W F}$ in parallel with an impedance $Z_{W F}$ due to its fast current control in its converters [18].

The HVDC could be simplified as a current source $I_{H V D C}$. The voltage at $V_{a c}$ could be expressed as:

$$
\left(\frac{1}{Z_{G}}+\frac{1}{Z_{W F}}\right) V_{a c}=\frac{V_{G}}{Z_{G}}+I_{W F}-I_{H V D C} .
$$

where $I_{H V D C}$ is the current phasor corresponding to the fundamental component in the rectifier ac current. It has a relationship with the dc current $I_{d R}$ :

$$
I_{H V D C}=\frac{\sqrt{6}}{\pi} I_{d R} \angle \phi
$$

where $\phi$ is the angle relative to the voltage phasor $V_{a c}$ and

$$
\phi=\cos ^{-1}\left(\frac{V_{d R}}{2.7 V_{a c} \cos \alpha}\right)
$$

As the wind speed increases, $I_{W F}$ will be raised. From the above expression, $V_{a c}$ will increase correspondingly. Power and current through the HVDC are expected to increase to absorb wind energy. Hence a positive feedback is reasonable. The controller is shown in Fig. 5 where $V_{a c}$ and the reference voltage are compared. The error is fed into a PI controller to generate the dc current order. With an increase in wind

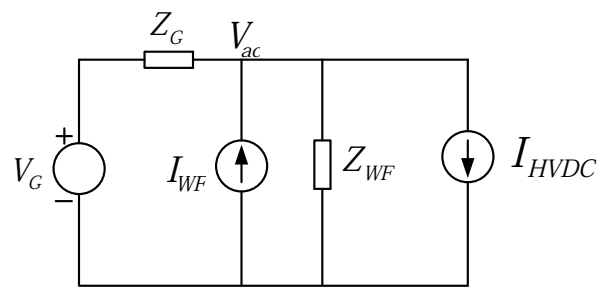

Fig. 6. Circuit representation of the study system.

speed, $V_{a c}$ increases which causes the HVDC current order increases. Through the firing angle control, the firing angle at the rectifier side reduces. This gives a rise in the dc current $I_{d R}$ and the dc rectifier side voltage $V_{d R}$. Thus more power will be transported through the HVDC system $\left(P=V_{d R} I_{d R}\right)$.

Such a feedback system can maintain its stability autonomously. When the firing angle reduces and the dc current increases, the ac current flowing into the HVDC $I_{H V D C}$ in turn will increase. Consequently $V_{a c}$ will reduce based on (1). When $V_{a c}$ finally matches its reference value, the current order will no longer be varied and the system reaches another operating point.

The objective of the LCC-HVDC is to route wind power to another grid while not to route the power from the synchronous generator. The current controller bandwidth is about $40 \mathrm{~Hz}$ while the synchronous generator's secondary frequency response usually needs a longer time to settle down to a constant frequency (more than 10s of seconds). However the synchronous generator's inertia response has a bandwidth of about $2 \mathrm{~Hz}$. Bode plots of the entire rotor speed control closedloop for the synchronous generator employed in the study system is shown in Fig. 7. It is found that at about 10rad/s, there is a resonance. This corresponds to the inertia dynamics of about $2 \mathrm{~Hz}$.

Therefore, the requirement of the voltage control is to act slower than the current controller to avoid interactions while act faster than the inertia response. The voltage control loop will chose to have a bandwidth between $2 \sim 40 \mathrm{~Hz}$. The lower and upper limit of the PI controller are 0.5 and 1.5 pu. In the design, different PI controller parameters and the corresponding responses towards a step change in wind power 
or load will be examined. In Fig. 11 in the next section, it will be demonstrated that when the voltage control acts faster to facilitate absorbing wind power change, the inertia response of the synchronous generator subjects to less power swing and frequency deviation. A less frequency deviation in turn will lead to a much less power sharing from the synchronous generator.

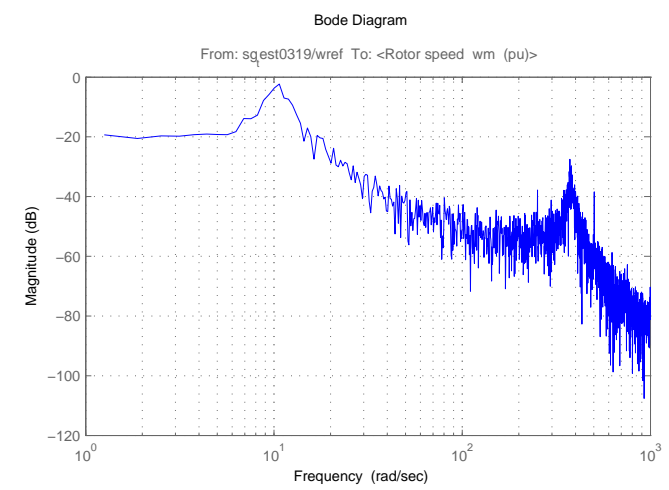

Fig. 7. Bode plot of the synchronous generator's frequency control closedloop system when the generator is connected to an infinite bus.

\section{Simulation Studies}

To demonstrate the power routing capability of the HVDC, simulation studies are carried out in Matlab/SimPowerSystems [13]. The study system is shown in Fig. 1. The synchronous generator supplies power to the HVDC (at about $500 \mathrm{MW}$ ) and the local load (420 MW). The DFIG-based wind farm is an aggregated system rated at $510 \mathrm{MW}$. Four case studies are designed. Case study 1 tests the voltage control step response. Case Study 2 tests HVDC's fast power routing capability when the wind speed changes. Case Study 3 tests HVDC's fast power routing capability when there is a change in loads and when the synchronous generator picks up the load change. Case Study 4 tests ac fault recovery of the HVDC system.

\section{A. Case Study 1: Step response of $V_{a c}$ setting}

In this case, the reference value of the ac voltage $V_{a c}^{*}$ is assumed to decrease from $0.985 \mathrm{pu}$ to $0.95 \mathrm{pu}$ at $t=15 \mathrm{~s}$. The voltage controller parameters are as follow: $K_{p}=0.2$ and $K_{i}=3.2$. Due to the positive feedback control, the dc current of the HVDC will increase and the firing angle will decrease. The dynamic responses of the rectifier and inverter variables are shown in Fig. 8. Power through HVDC will increase too (about $50 \mathrm{MW}$ ). Fig. 9 shows power from the synchronous generator, the DFIG-based wind farm and power through HVDC. The response time for the HVDC is about only 1 second. Due to the power control enforced in the wind farm, power from the wind farm vary insignificantly. The ac grid should experience a frequency decrease and the synchronous generator generates more power to match the HVDC power increase.

The reactive power absorbed by the HVDC rectifier reduces due to a decrease in the firing angle $(Q \propto \sin \alpha)$. Reactive power from the wind farm is tightly controlled and does not vary at steady-state.
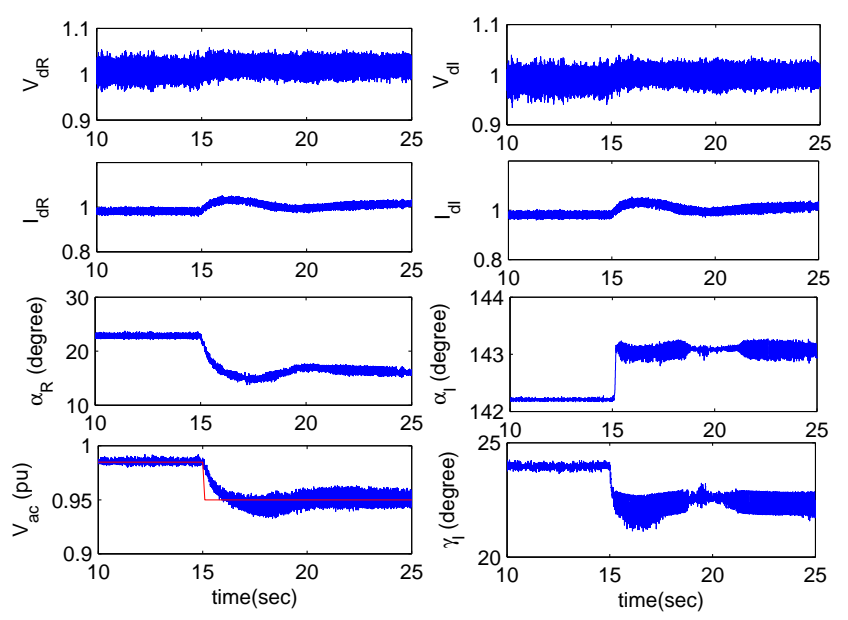

Fig. 8. Dynamic responses of the HVDC system due to a step response in $V_{a c}^{*}$.
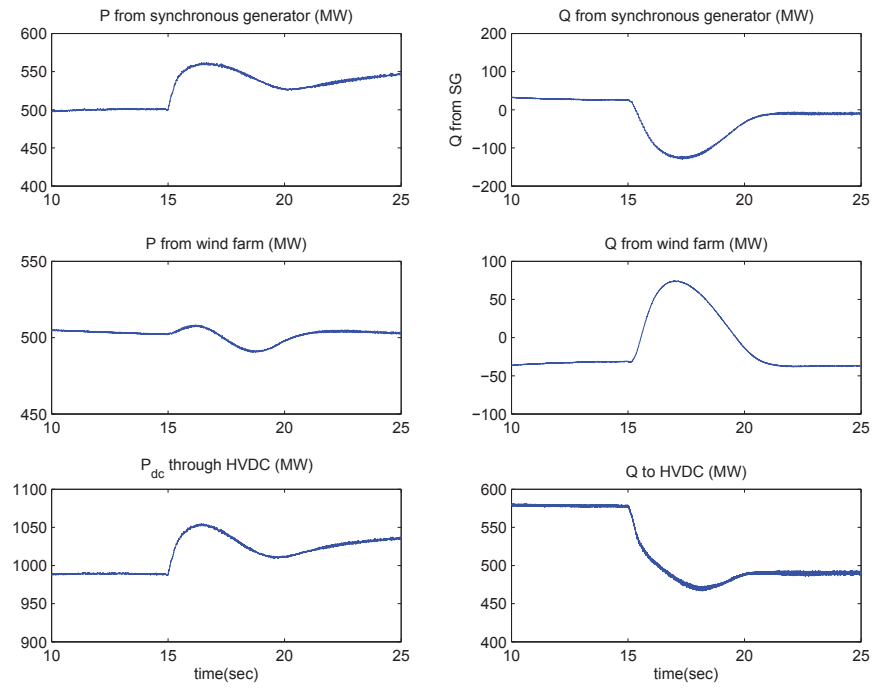

Fig. 9. Dynamic responses in active and reactive power due to a step response in $V_{a c}^{*}$.

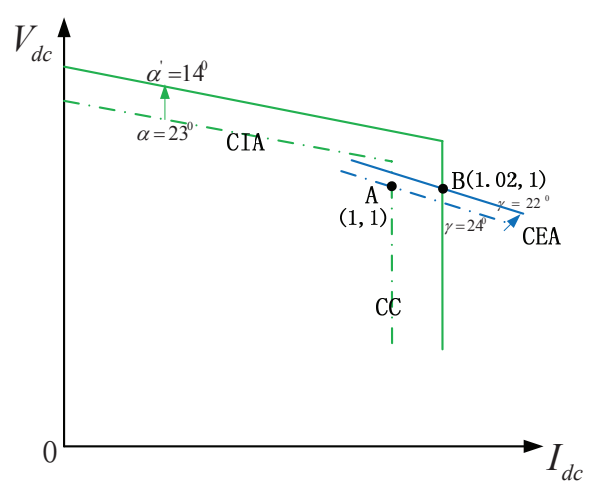

Fig. 10. V-I characteristics of the HVDC. CIA: constant ignition angle; CEA: constant extinction angle. 
The dc currents increase and the rectifier firing angle decreases due to the step response. The relationship of the dc voltage and current is shown in Fig. 10. An increase in the ac voltage results in an increase in $V_{d c 0}$ the cross point of the rectifier CIA line and the Y-axis. The inverter is at constant voltage control. While the original operating condition is at point $\mathrm{A}$, due to the increase of the dc current, the operating point moves to B. Inverter dc voltage levels at A and B are kept same. Extinction angle $\gamma$ will decrease when the operating point moves from A to B. Hence in Fig. 8, we can also observe that $\gamma$ decreases due to a reduction in the ac voltage reference value.

\section{B. Case Study 2: Wind speed change}

A varying wind speed is the main characteristic of wind energy. In this case, the power routing capability of HVDC is tested for a varying wind speed. The voltage controller is the key for the HVDC to pick up power change under different wind speeds. However, different PI parameter settings can affect the power sharing of the DFIG, the synchronous generator and the HVDC. When the time constant of the voltage controller is small, the HVDC will pick up all the power change when the wind speed changes. When the time constant of the PI controller is large, the synchronous generator and HVDC will share the power change. Fig. 11 shows the comparison of two cases with different time constants. In (a), the parameters are $K_{p}=0.7, K_{i}=0.9$, and the time constant $\tau=0.76$. The synchronous generator and the HVDC will pick up the power change from the DFIG together. The share of the synchronous generator is about $15 \mathrm{MW}$. In (b), $K_{p}=0.2$, $K_{i}=3.2$, and the time constant $\tau=0.0625$. The HVDC acts fast enough to pick up all the power change from the wind farm.
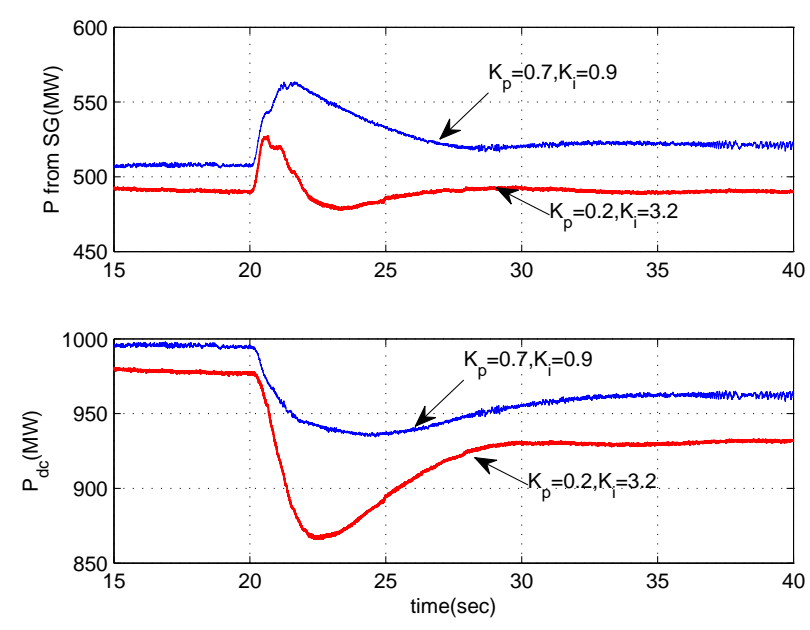

Fig. 11. Dynamic responses of active power from synchronous generator, through HVDC due to a change in wind speed under different PI controller settings.

From Fig. 12, it is found that in Case b the response of $V_{a c}$ is much faster compared to that in Case a. Therefore a faster voltage control can avoid power sharing by the synchronous generator.
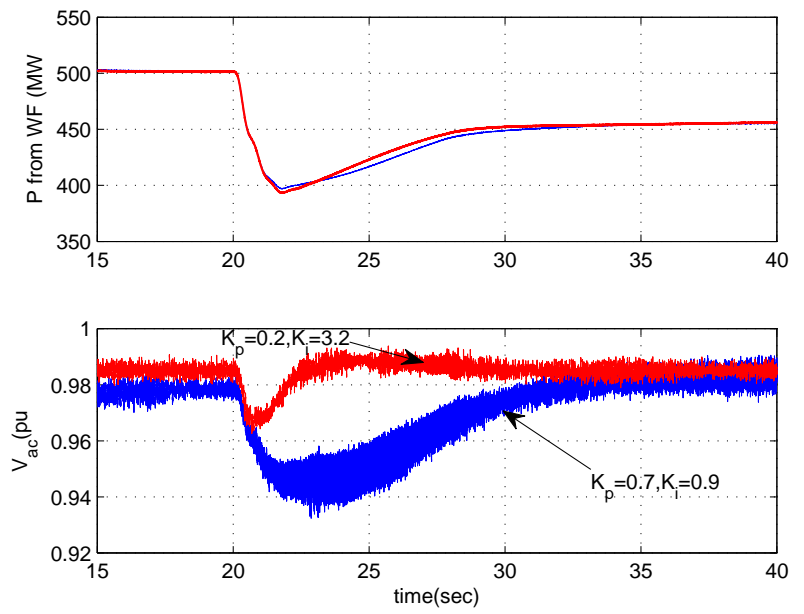

Fig. 12. Dynamic responses of active power from DFIG and $V_{a c}$ due to a change in wind speed under different PI controller settings.

A more complicated case is presented as follows. The controller parameters are chosen to be $K_{p}=0.2, K_{i}=3.2$. The wind speed drops from $15 \mathrm{~m} / \mathrm{s}$ to $12 \mathrm{~m} / \mathrm{s}$ at 10 seconds. It then increases from $12 \mathrm{~m} / \mathrm{s}$ to $17 \mathrm{~m} / \mathrm{s}$ at $20 \mathrm{~seconds}$. Dynamic responses of the power from the generator, the wind farm and through the HVDC are given in Fig. 13. The generator speed and the mechanical power are shown in Fig 14. The input variable $V_{a c}$ and output variable $I_{d r e f}$ of the controller are shown in Fig. 14. The HVDC variables are shown in Fig. 15 and the DFIG system variables are shown in Fig. 16.

At $t=10$ second, the wind speed drops from $15 \mathrm{~m} / \mathrm{s}$ to $12 \mathrm{~m} / \mathrm{s}$. A drop in wind speed leads to a drop in wind farm active power export (Fig. 13), a decrease of the HVDC rectifier side ac voltage $V_{a c}$ (Fig. 14), a decrease of the dc current order $I_{d r e f}$ (Fig. 14) and the dc current $I_{d}$ (Fig. 15), an increase in the firing angle $\alpha_{R}$ (Fig. 15) and a decrease of HVDC delivered power $P_{d c}$ (Fig. 13). The response of the HVDC power has a delay compared to the response of the wind farm power. The synchronous generator has an initial increase of power export to balance the total power by releasing kinetic energy from its rotating mass. This leads to the reduction of its rotating speed. The turbine governor senses the change in rotating speed and generator power and adjusts its mechanical power based on the error signal.

The DFIG pitch angle will become zero when the wind speed reduces below the synchronous speed.

\section{Case Study 3: Load change}

In Case Study 3, the load increases from $420 \mathrm{MW}$ to 520 MW at 10s. The HVDC picks up the load change immediately since the response of the HVDC is faster than the synchronous generator. Due to the slow turbine governor response, a change in the reference power $P_{\text {ref }}$ will be reflected in the generator power after about 30 seconds. In order to show the HVDC response in this simulation case, the mechanical power of the synchronous generator is assumed to have an increase of 100 MW at 15 seconds. The synchronous generator will increase 

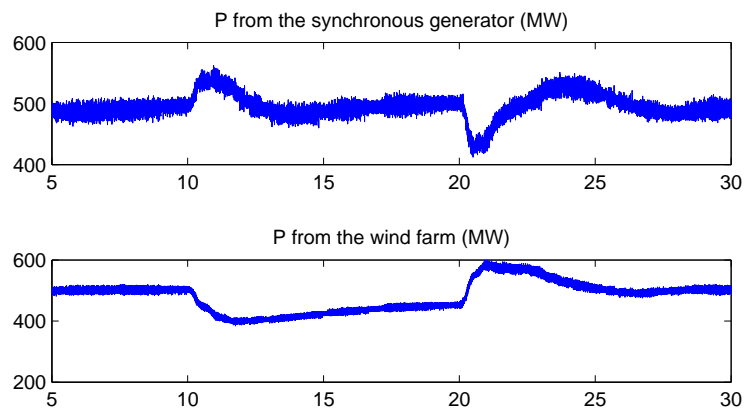

$P_{d c}$ of the HVDC

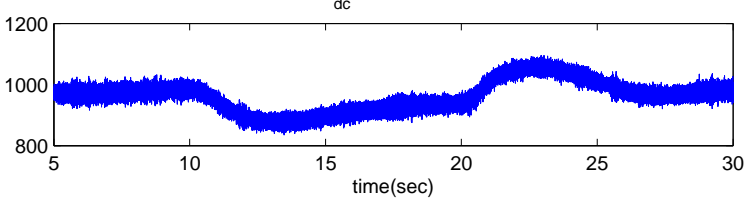

Fig. 13. Dynamic responses of the real power from the synchronous generator (excluding the load), the wind farm and through the HVDC due to wind speed changes.
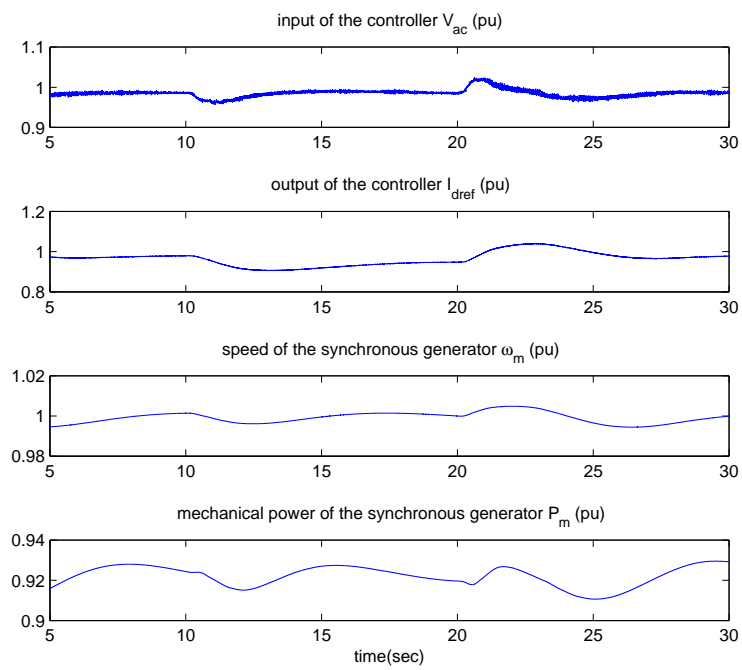

Fig. 14. Dynamic responses of the voltage controller and the turbine governor due to wind speed changes.

its power output to pick up the load change. Consequently, the dc power will be reduced to its original level. Dynamic responses of the system are shown in Figs. 17 and 18.

The synchronous generator speed will decrease when the load increases and will increase when the synchronous generator increases its output power. Increased load however affects the system voltage level. $V_{a c}$ will decrease. This in turn will trigger the voltage controller to decrease the dc current order and increase the firing angle. When the synchronous generator starts to pick up the load increase, the voltage level increases. The HVDC system will then ramp up its transporting power through decreasing the rectifier firing angle $\alpha$.

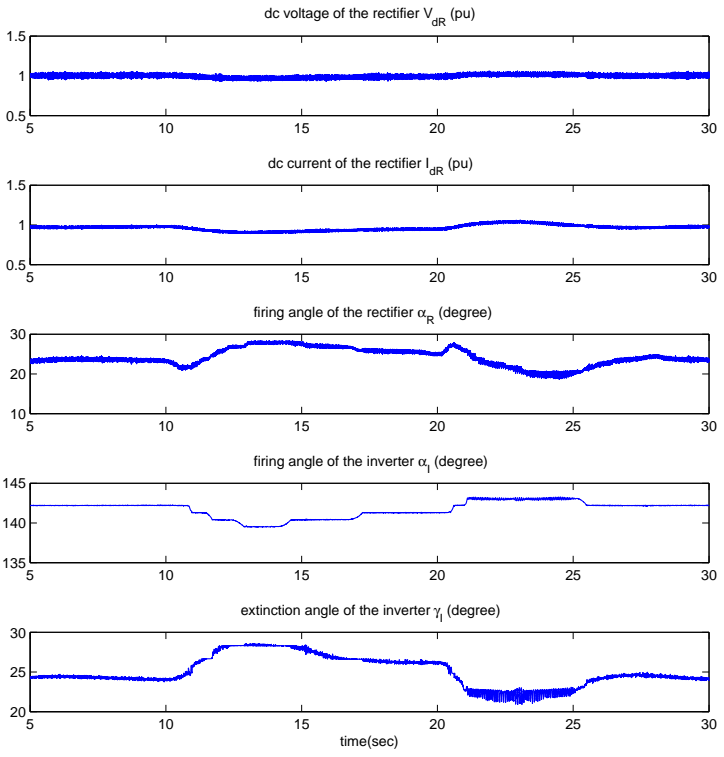

Fig. 15. Dynamic responses of the HVDC due to wind speed changes.
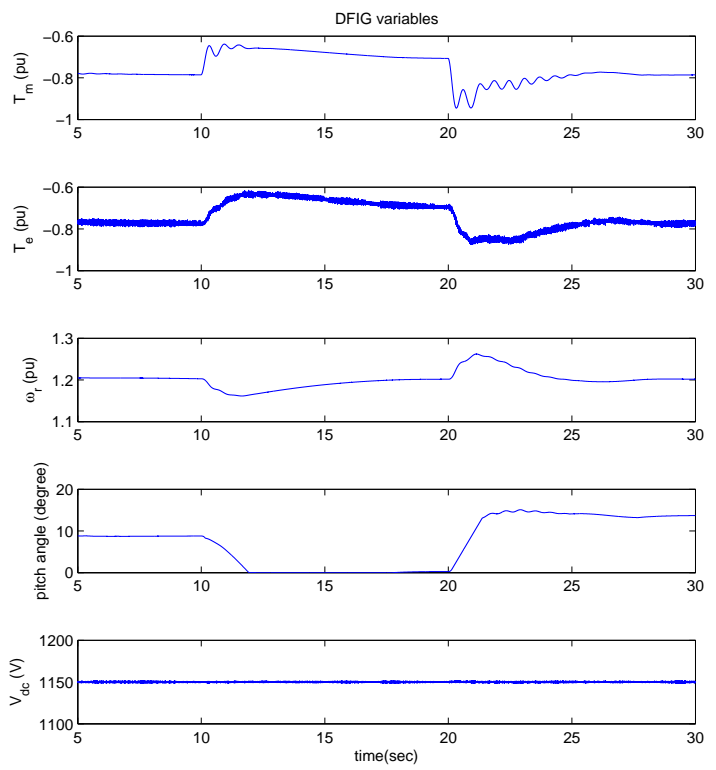

Fig. 16. Dynamic responses of the DFIG wind farm due to wind speed changes. 


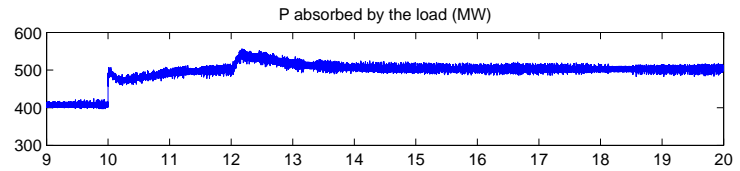

$\mathrm{P}_{\text {ref }}$ of the synchronous generator(MW)
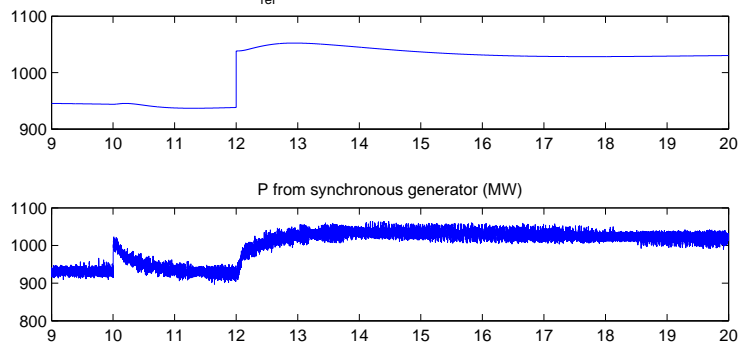

$P_{d c}$ through HVDC line (MW)

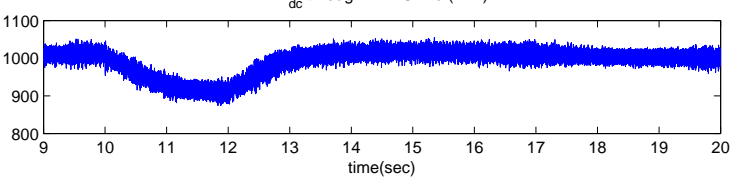

Fig. 17. Dynamic responses of the active power from synchronous generator, load, DFIG and through HVDC due to a load change.
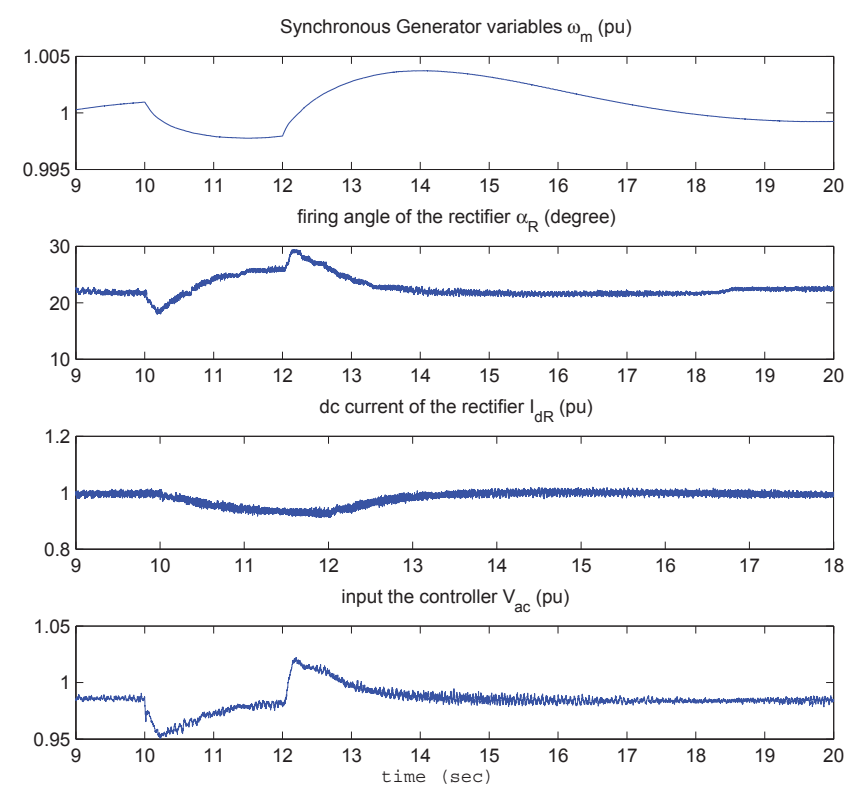

Fig. 18. Dynamic responses of the generator speed, firing angle, dc voltage and $V_{a c}$ due to load change.

\section{Case Study 4: AC fault recovery}

The operation of an HVDC is often affected by disturbances such as faults on the ac system. In Case Study 4, a single-lineto-ground (S-L-G) fault on the inverter ac system is studied. A S-L-G fault is applied on phase A at $10 \mathrm{~s}$, and is cleared at $10.1 \mathrm{~s}$. The fault will cause the reduction of the ac voltage and raise of the dc current as shown in Fig. 19. Due to the failure of the commutation from one valve to another before the commutating voltage reverses, commutation failure occurs at the very beginning of the fault. The commutation failure will lead to short circuit across the valve group. The dc power is almost zero as shown in Fig. 20. After the fault is cleared, the system returns to normal operation after about $0.2 \mathrm{~s}$.

As shown in Case Study 2, the parameters of the voltage control affect system dynamics. The impact of the PI parameters on ac fault recovery performance is also studied. If the integration constant $K_{i}$ increases, the settling time of the system will increase [19]. Therefore, the dynamics of the $\mathrm{dc}$ current and firing angle of the rectifier will be affected under different integration constants. Figs. 19 and 20 show that when $K_{i}=3$, the system can not recovery after the fault clearance. Therefore, the two other two sets of parameters $K_{p}=0.2 / K_{i}=1.5$ and $K_{p}=0.2 / K_{i}=2$ are better in terms of ac fault recovery.

In Case Study 2, a smaller time constant is demonstrated to be good for HVDC to do fast power routing task. However, Case Study 4 shows that a smaller time constant for the PI controller may cause ac fault recovery problems. Therefore, the controller parameters have to be chosen and verified through various studies.

\section{CONCLUSION}

This paper investigates the fast power routing capability of LCC-HVDC. A positive feedback control loop is introduced in the rectifier control to produce the dc current order. Matlab/SimPowersystems based simulation for an ac/dc system with wind power penetration confirms the effectiveness of such control scheme. In addition, ac fault recovery is investigated for an LCC-HVDC equipped with the proposed control scheme. The proposed technology can help realize fast power routing through LCC-HVDC in future grid with high penetration of intermittent renewable energy resources.

\section{APPENDIX}

TABLE I

PARAMETERS OF THE DFIG WIND FARM

\begin{tabular}{|c|c|}
\hline Total capacity & $333^{*} 1.5 \mathrm{MW}$ \\
Nominal voltage & $575 \mathrm{~V}$ \\
Frequency & $60 \mathrm{~Hz}$ \\
$r_{s}(p u)$ & 0.023 \\
$r_{r}(p u)$ & 0.18 \\
$X_{l s}(p u)$ & 0.016 \\
$X_{l r}(p u)$ & 0.16 \\
$X_{M}(p u)$ & 2.9 \\
$H\left(k g . m^{2}\right)$ & 0.685 \\
$F(p u)$ & 0.01 \\
$p($ poles $)$ & 3 \\
\hline
\end{tabular}

\section{REFERENCES}

[1] P. Bresesti, W. Kling, R. Hendriks, and R. Vailati, "HVDC connection of offshore wind farms to the transmission system," IEEE Trans. Energy Convers., vol. 22, no. 1, pp. $37-43$, Mar. 2007.

[2] L. Xu and B. R.Andersen, "Grid connection of large offshore wind farms using HVDC," Wind Energy, vol. 9, no. 4, pp. 371-382, Dec. 2005.

[3] L. Xu, L. Yao, and C. Sasse, "Grid integration of large DFIG-based wind farms using VSC transmission," IEEE Trans. Power Syst., vol. 22, no. 3, pp. $976-984$, Aug. 2007. 

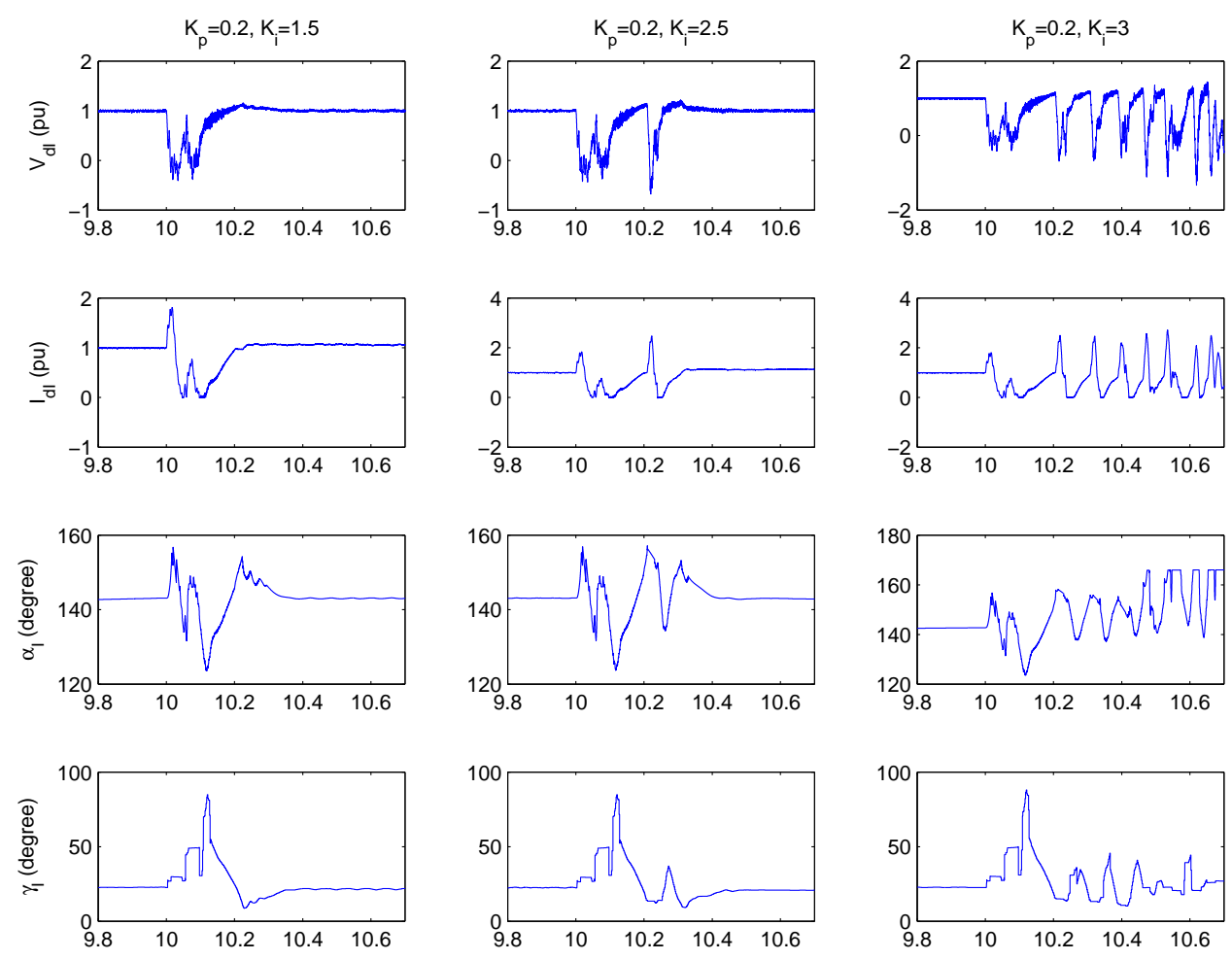

Fig. 19. Dynamics of the inverter variables during A-L-G fault at the inverter side.
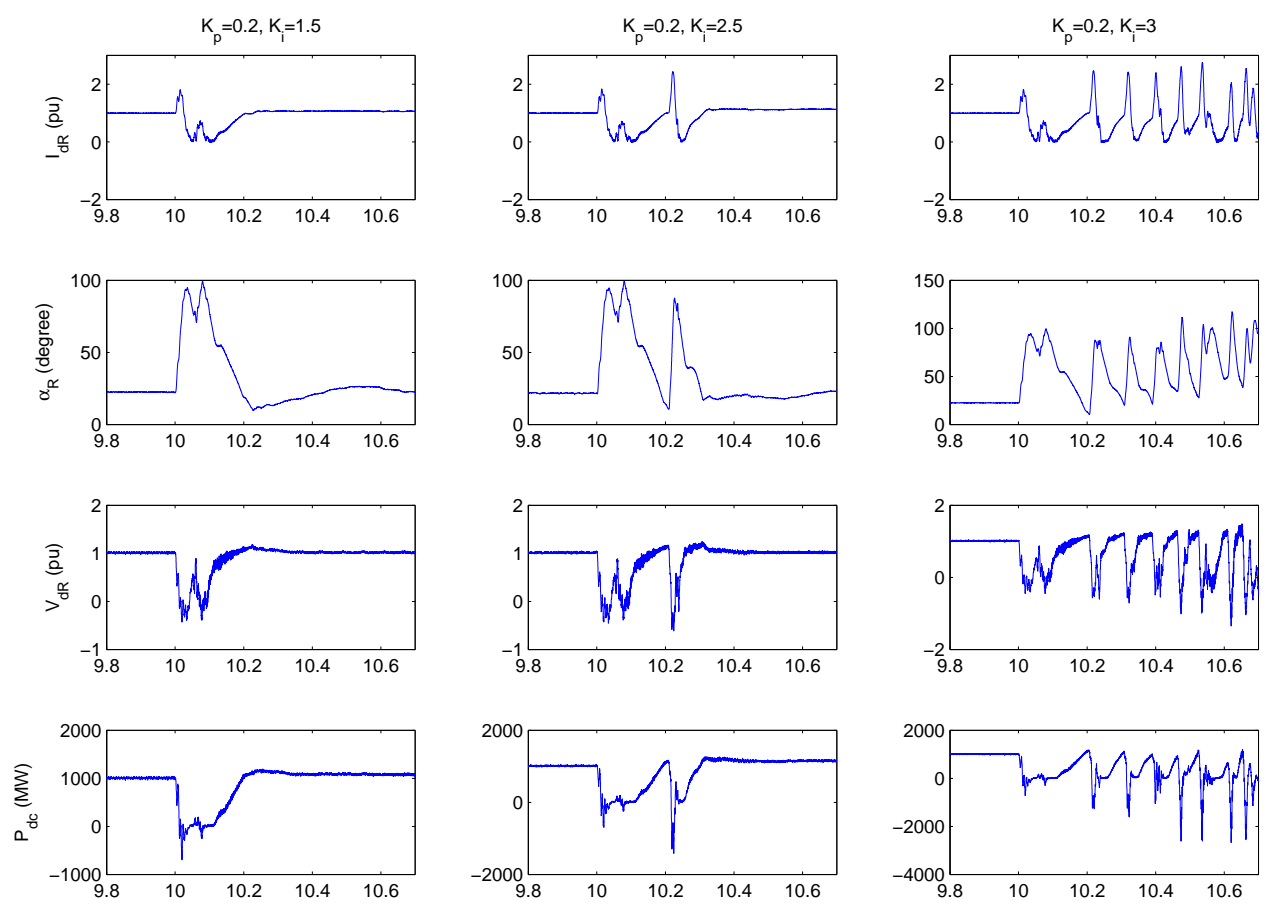

Fig. 20. Dynamics of the rectifier variables during A-L-G fault at the inverter side. 
[4] N. Flourentzou, V. Agelidis, and G. Demetriades, "VSC-based HVDC power transmission systems: an overview," IEEE Trans. Power Electron., vol. 24, no. 3, pp. $592-602$, March 2009.

[5] V. K. Sood, HVDC and FACTS Controllers:Applications of Static Converters in Power Systems. Springer, 2004.

[6] P. Kundur, Power System Stability and Control. McGraw Hill, 1994.

[7] S. Bozhko, R. Blasco-Gimenez, R. Li, J. Clare, and G. Asher, "Control of offshore DFIG-based wind farm grid with line-commutated HVDC connection," IEEE Trans. Energy Convers., vol. 22, no. 1, pp. 71 -78, Mar. 2007.

[8] D. Xiang, L. Ran, J. Bumby, P. Tavner, and S. Yang, "Coordinated control of an HVDC link and doubly fed induction generators in a large offshore wind farm," IEEE Trans. Power Del., vol. 21, no. 1, pp. 463 471, Jan. 2006.

[9] R. Li, S. Bozhko, and G. Asher, "Frequency control design for offshore wind farm grid with LCC-HVDC link connection," IEEE Trans. Power Electron., vol. 23, no. 3, pp. 1085 -1092, May 2008.

[10] S. Bozhko, G. Asher, R. Li, J. Clare, and L. Yao, "Large offshore DFIGbased wind farm with line-commutated HVDC connection to the main grid: Engineering studies," IEEE Trans. Energy Convers., vol. 23, no. 1, pp. $119-127,2008$

[11] S. Foster, L. Xu, and B. Fox, "Control of an lcc hvdc system for connecting large offshore wind farms with special consideration of grid fault," in Power and Energy Society General Meeting - Conversion and Delivery of Electrical Energy in the 21st Century, 2008 IEEE, july 2008, pp. $1-8$.

[12] H. Zhou, G. Yang, and J. Wang, "Modeling, analysis, and control for the rectifier of hybrid HVdc systems for DFIG-based wind farms," IEEE Trans. Energy Convers., vol. 26, no. 1, pp. 340 -353, Mar. 2011.

[13] Simpowersystems ${ }^{T M}$. Mathworks. [Online]. Available: http://www.mathworks.com/help/toolbox/physmod/powersys/ powersys_product_page.html

[14] Simpowersystems ${ }^{T} M_{-}$hydraulic turbine and governor. Mathworks [Online]. http://www.mathworks.com/help/toolbox/physmod/powersys/ref/ hydraulicturbineandgovernor.html

[15] "Modeling of ge wind turbine-generators for grid studies," General Electric International, Inc, Schenectady, New York, Tech. Rep., 2005.

[16] T. K. A. Brekken and N. Mohan, "Control of a doubly fed induction wind generator under unbalanced grid voltage conditions," IEEE Trans. Energy Convers., vol. 22, no. 1, pp. 129-135, Mar. 2007.

[17] R. Pena, J. Clare, and G. Asher, "Doubly fed induction generator using back-to-back pwm converters and its application to variable-speed windenergy generation," Proc. Inst. Elect. Eng. Elect. Power Appl., vol. 143 , no. 3, pp. 231-241, 1996.

[18] "Modeling of GE wind turbine-generators for gid studies," GE Energy, Schenectady, NY, Tech. Rep., Mar. 2005

[19] PID tutorial. The University of Michigan. [Online]. Available: http://www.engin.umich.edu/group/ctm/PID/PID.html\#introduction

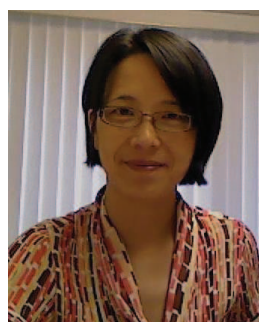

Lingling Fan (SM'08) received the B.S. and M.S. degrees in electrical engineering from Southeast University, Nanjing, China, in 1994 and 1997, respectively, and the Ph.D. degree in electrical engineering from West Virginia University,Morgantown, in 2001 .

Currently, she is an Assistant Professor with the University of South Florida, Tampa, where she has been since 2009. She was a Senior Engineer in the Transmission Asset Management Department, Midwest ISO, St. Paul, MN, form 2001 to 2007, and an Assistant Professor with North Dakota State University, Fargo, from 2007 to 2009. Her research interests include power systems and power electronics.

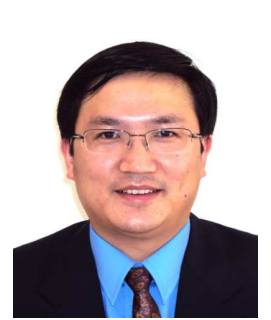

Zhixin Miao (S00M03SM09) received the B.S.E.E. degree from the Huazhong University of Science and Technology, Wuhan, China, in 1992, the M.S.E.E. degree from the Graduate School, Nanjing Automation Research Institute; Nanjing, China, in 1997, and the $\mathrm{Ph} . \mathrm{D}$. degree in electrical engineering from West Virginia University, Morgantown, in 2002.

Currently, he is with the University of South Florida (USF), Tampa. Prior to joining USF in 2009, he was with the Transmission Asset Management Department with Midwest ISO, St. Paul, MN, from 2002 to 2009. His research interests include power system stability, microgrid, and renewable energy.

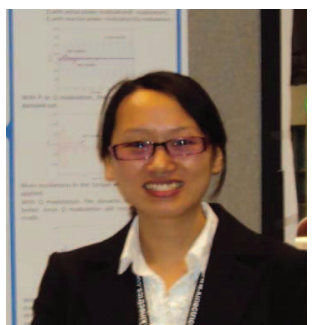

Haiping Yin '09'09S received a Ph.D. degree in Electrical Engineering from University of South Florida in 2011. Currently she is an engineer at PWR Solutions at Dallas Texas. Her research interests include modeling and control of wind energy systems, electrical power systems and HVDC transmission. 